(2) Open Access Full Text Article

\title{
Downregulated Ku70 and ATM associated to poor prognosis in colorectal cancer among Chinese patients
}

This article was published in the following Dove Press journal:

OncoTargets and Therapy

24 October 2014

Number of times this article has been viewed

\section{Yuanfang Lu $u^{1,2}$ \\ Jingyan $\mathrm{Gao}^{1,3}$ \\ Yuanming $\mathrm{Lu}^{\prime}$}

'Department of Toxicology, School of Public Health, Guilin Medical

University, Guangxi, People's

Republic of China; '2Department of

Clinical Research Center, Affiliated

2nd Hospital of Nanjing Medical

University, Nanjing, People's Republic

of China; ${ }^{3}$ Department of Human

Anatomy and Histo-Embryology,

Shanghai Medical College, Fudan

University, Shanghai, People's

Republic of China
Correspondence:Yuanming Lu

Department of Toxicology, School

of Public Health, Guilin Medical University,

North Huancheng 2nd Road, Guilin

541004, Guangxi, People's

Republic of China

Tel +867732235932

Email bobojpn@hotmail.com
Background: Double-strand DNA breaks (DSBs) are a key factor in carcinogenesis. The necessary repair of DSBs is pivotal in maintaining normal cell division. To address the relationship between altered expression of DSB repair of proteins $\mathrm{Ku} 70$ and ataxia-telangiectasia mutated (ATM) in colorectal cancer (CRC), we examined the expression levels and patterns of Ku70 and ATM in CRC samples.

Methods: Expression and coexpression of Ku70 and ATM were investigated by using real-time quantitative polymerase chain reaction assays and confirmed further with fluorescent immunohistochemistry in CRC and pericancerous samples from 112 Chinese patients.

Results: Downexpression patterns for both $\mathrm{Ku} 70$ and ATM were found in the CRC samples and were significantly associated with advanced tumor node metastasis stage and decreased 5-year overall survival rate.

Conclusion: Downregulated Ku70 and ATM were associated with poor disease-free survival. Loss of $\mathrm{Ku} 70$ and ATM expression might act as a biomarker to predict poor prognosis in patients with CRC.

Keywords: DNA double-strand breaks, ataxia-telangiectasia mutated, Ku70, colorectal cancer

\section{Introduction}

Colorectal cancer (CRC) develops from a small benign tumor, for example, adenomatous polyps, to a malignant cancer through a series of defined histopathological stages. ${ }^{1}$ Genetic changing to inactivation of tumor suppressor genes (eg, p53) and the activation of oncogenes (eg, $K$-ras, $\beta$-catenin) occurred in this progression. ${ }^{2}$ The levels of genomic alterations in cancer cells apparently exceed that in normal cells. Intricate networks have evolved in eukaryotic cells to respond to exogenous and endogenous genotoxic stimuli in the process of tumor development. ${ }^{3}$ Genes involved in the networks are essential to maintain DNA integrity, and any defects occurring in these processes might affect the DNA damaging agents and genomic instability. ${ }^{4}$

DNA double-strand breaks (DSBs) are the most critical factor in all DNA lesions; ;,6 defects in cellular response to DSBs can develop in to genetic alteration, chromosomal instability, and ultimately malignant transformation. ${ }^{7}$ Ataxia-telangiectasia mutated (ATM) is a serine-threonine kinase that is triggered by DSBs to activate several downstream targets, including those involved in the induction of cell senescence and apoptosis. ${ }^{8} \mathrm{Ku} 70$ can form a Ku heterodimer complex with Ku80 that binds to DSBs and aids in nonhomologous end joining (NHEJ). 
Few studies have examined the expression of DSB repair proteins in CRC carcinogenesis. The currently available literature on DNA DSB repair and CRC is limited and controversial, particularly regarding Ku70 and ATM coexpression with poor disease-free survival (DFS). We therefore analyzed the expression level of the DNA repair proteins ATM and $\mathrm{Ku} 70$ using real-time quantitative polymerase chain reaction (QPCR) and further examined the coexpression pattern of ATM and Ku70 by fluorescent immunohistochemistry (IHC) in samples from 112 Chinese patients with CRC, and explored the expression of $\mathrm{Ku} 70$ and ATM association to the clinicopathologic index and the estimated survival rates of patients.

\section{Materials and methods Patients}

One-hundred and twelve patients with CRC were selected for sample collection, and none of them had received any chemotherapy or radiotherapy before surgery in the affiliated hospital, Guilin Medical University. Resected specimens were reviewed by two senior pathologists according to the criteria described in the American Joint Committee on Cancer Staging Manual (7th edition, 2010). ${ }^{9}$ Fresh tumor tissues and pericancerous normal tissue were collected and immediately washed with phosphate-buffered saline (PBS), and stored in liquid nitrogen at $-80^{\circ} \mathrm{C}$ in our tissue bank until further use. Ethical approval was obtained from the Guilin Medical University Cancer Center Research Ethics Committee, and written informed consent was obtained from all participants.

\section{RNA isolation and reverse transcription}

Total RNA was isolated from the human tissue using the Invitrogen (Thermo Fisher Scientific, Waltham, MA, USA) TRizol according to the manufacturer's instructions. The RNA concentration was measured, the integrity was analyzed further, and a total of $1 \mu \mathrm{g}$ of RNA was used to reversetranscribe cDNA, according to the manufacturer's protocol (Promega Corporation, Fitchburg, WI, USA).

\section{Real-time quantitative PCR}

SYBR green supermix (Promega) was applied in real-time QPCR. Ten nanograms of RT mix in a $25-\mu \mathrm{L}$ reaction mixture was used for the PCR reaction system by the ABI Prism 7700 sequence detector system (Applied Biosystems, Branchburg, NJ, USA). The target genes were normalized to $\beta$-actin and quantified using the comparative $\mathrm{Ct}$ method. ${ }^{10}$ The expression levels of $K u 70$ and ATM were measured in triplicate with good reproducibility, and the average values were calculated.

Primers for $\beta$-actin (205 b p) were 5'-TGACGTGGACATCCGCAAAG-3' (sense) and 5'-CTGGAAGGTGGACAGCGAGG-3' (antisense).

Primers for $K u 70 \quad(131$ b p $)$ were 5'-TGCCACAGGAAGAAGAGTTG-3' (sense) and 5'-CTCTGGAGTTGCCATGATTT-3' (antisense).

Primers for $A T M \quad(156$ b p $)$ were 5'-TGTGACTTTTCAGGGGATTTG-3'(sense) and 5'-ATAGGAATCAGGGCTTTTGGA-3'.

\section{Western blotting}

Briefly, 30- $\mu$ g protein samples from each case were separated with $10 \%$ sodium dodecyl sulfate polyacrylamide gel electrophoresis; furthermore, transferring poly(vinylidene fluoride) membranes were used for the blot. Membranes were incubated separately with anti-Ku70 or anti-ATM first rabbit polyclonal antibody (1:1000 dilution), and then incubated in the horseradish peroxidase conjugated secondary antibody buffer (1:100 dilution). $\beta$-actin was used as a loading control (anti- $\beta$-actin, 1:1000 dilution) simultaneously. All blots were visualized using an ECL detection system (Amersham, Arlington Heights, IL, USA) and quantitated by densitometry using an LAS-3000 imager.

\section{$\mathrm{IHC}$ and assessment of staining patterns}

Tissue sections of $5 \mu \mathrm{m}$ thickness were subjected to antigen retrieval. Staining was performed using the Vectastain Elite ABC System (Vector Laboratories, Burlingame, CA, USA) according to manufacturer's instructions. The diaminobenzidine peroxidase substrate kit (Vector Laboratories) was used for color developing, and sections were counter-stained with hematoxylin (Sigma Aldrich, St Louis, MO, USA). Commercially available $\mathrm{Ku} 70$ and ATM antibodies were purchased and used at the recommended ratio (dilution 1:100). Imaging was carried out with an Olympus IX51 microscope (Olympus Corporation, Tokyo, Japan) and positively quantified using the NIH Image J64 software (threshold standardized; measurement determined as percent area: red).

For the immunocytofluorescence assay, tissues were fixed on eight-well chamber slides and fixed in ice-cold acetone. After fixation, the cells were blocked in $1 \%$ bovine serum albumin and 5\% normal goat serum PBS solution, stained in the indicated primary antibody buffer overnight at $4^{\circ} \mathrm{C}(1: 100$ dilution), and further washed and incubated in the secondary antibody buffer (1:1000 dilution, Invitrogen) for another 1 hour. After DNA staining with 
4',6-diamidino-2-phenylindole (DAPI), cover slips were further fixed with mounting medium with DAPI (Vector Laboratories). The imaging was observed with a Carl Zeiss LSM510 (Carl Zeiss Meditec AG, Jena, Germany) confocal imaging system. Cells positively stained for $\mathrm{Ku} 70$ or ATM expression were counted in three separate $40 \times$ fields; a minimum of three glands per developmental stage were counted.

For primary antibodies, we used anti-Ku70 mouse monoclonal antibodies (Abcam, Cambridge, UK), and ATM rabbit monoclonal antibodies (EMD Millipore, Billerica, MA, USA) in the IHC tests. Full tissue sections of 112 pairs of paraffin-embedded CRC and pericancerous normal tissues were processed for IHC staining of Ku70 and ATM. Tumor cells were considered $\mathrm{Ku} 70^{+}$and $\mathrm{ATM}^{+}$if they displayed any immunoreactivity, regardless of the staining intensity.

Primary antibodies for light microscopic immunocytochemistry were visualized by fluorescein isothiocyanate-conjugated goat anti-rabbit and goat antimouse antibodies (Thermo Fisher Scientific, Waltham, MA, USA), tetramethylrhodamine isothiocyanate-conjugated swine anti-rabbit (Dakopatts, Dako Denmark A/S, Glostrup, Denmark) IgG antibodies, or peroxidase conjugated protein A (Sigma).

\section{Statistical analysis}

Student's $t$-test was applied for calculating the differences in Ku70 and ATM expression between CRC and normal pericancerous tissues. The $\chi^{2}$ test was applied for evaluating the correlations between $\mathrm{Ku} 70$ and ATM expression and pathological indexes separately. Cumulative survival probability was estimated with the Kaplan-Meier method; differences were calculated by the log-rank test. Prognostic factors were determined using cox regression analysis. The overall survival times were assessed from the first resection of the primary tumor to death from any cause. $P<0.05$ was considered to be significant with two-sided values. Statistical analyses were performed using the SPSS 13.0 software.

\section{Results \\ Expression of Ku70 and ATM in pericancerous normal tissue and CRC samples}

Real-time QPCR was used to analyze Ku70 and ATM expression in CRC and pericancerous normal tissue. The relative gene expression quantifications were calculated according to the comparative $\mathrm{Ct}$ method using $\beta$-actin as an endogenous control. Both Ku70 and ATM mRNA expressions were downregulated in CRC compared to pericancerous normal tissues. Correlations of $\mathrm{Ku} 70$ to ATM expression levels $\left(R^{2}=0.9364 ; P<0.001\right)$ were calculated with relative expression level of Ku70 and ATM in cancer group separately, and the results are shown in Figure 1. The coexpression pattern of downregulation of Ku70 and ATM was confirmed further in the CRC samples with fluorescent IHC staining. Confocal microscopy showed a pattern of coexpressed Ku70 and ATM. Downregulation of Ku70 and ATM was observed in cancer tissues compared to pericancerous tissues (data not shown).

\section{Correlations of Ku70 and ATM expression to pathological features and postoperative prognosis of patients with CRC}

Correlations of Ku70 and ATM expression to pathological features were evaluated further; whether Ku70 and ATM levels could predict the clinical outcomes for patients with CRC was also assessed with an IHC assay in the same sample sets.

The results showed that positive expressions of $\mathrm{Ku} 70$ and ATM were significantly associated with the lymph node metastasis (LNM) and the advanced tumor node metastasis (TNM) stage $(P<0.001$, Table 1$)$. No correlations were found between $\mathrm{Ku} 70$ or ATM expression and other pathological parameters, for example, sex, age, tumor size, tumor differentiation, and tumor location.

Furthermore, we found that patients whose CRC specimens were negative for $\mathrm{Ku} 70$ or ATM had poorer prognoses than those with $\mathrm{Ku} 70^{+} / \mathrm{ATM}^{+} \mathrm{CRC}$ (Figure 2). The 5-year estimated probability of cumulative survival rate also differed between the patient groups with $\mathrm{Ku} 70^{-}$or $\mathrm{ATM}^{-} \mathrm{CRC}$ and the $\mathrm{Ku} 70^{+}$or $\mathrm{ATM}^{+}$group $(P<0.05)$. Univariate analyses results showed that LNM, TNM stage, Ku70, and ATM expression resulted in the overall survival. In multivariate analysis, LNM, TNM stage, Ku70, and ATM expression were correlated to the overall survival $(P<0.05$, Table 2$)$.

\section{Discussion}

The key components for NHEJ repair system are conserved from yeast to mammals and consist of the $\mathrm{Ku} 70$ / Ku80 heterodimer. ${ }^{11-13}$ DNA-PK catalytic subunits and DNA PKcs are also essential for the repair of a simple DSB in vivo. The appearance of blunt-end 3'-hydroxyl and $5^{\prime}$-phosphate DNA DSBs induces significantly more frequent anaphase bridges in cells that do not contain functional DNA-PKcs, which implies that DNA-PKcs affect chromosomal stability during end-joining. These minimal blunt-end DSBs are sufficient to induce the p53 and ATM/ ATR checkpoint functions. ${ }^{14}$ 
A

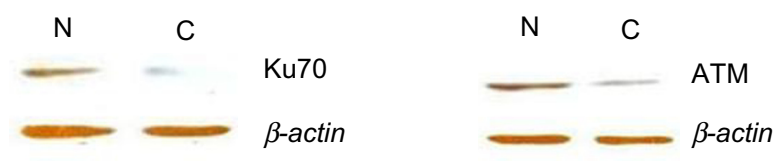

B
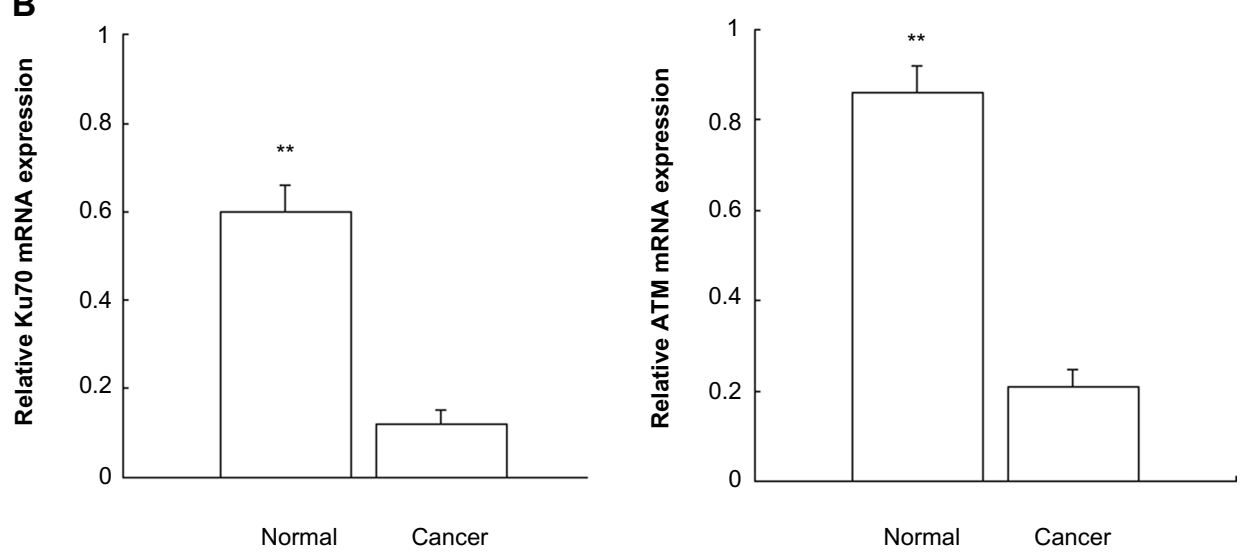

C

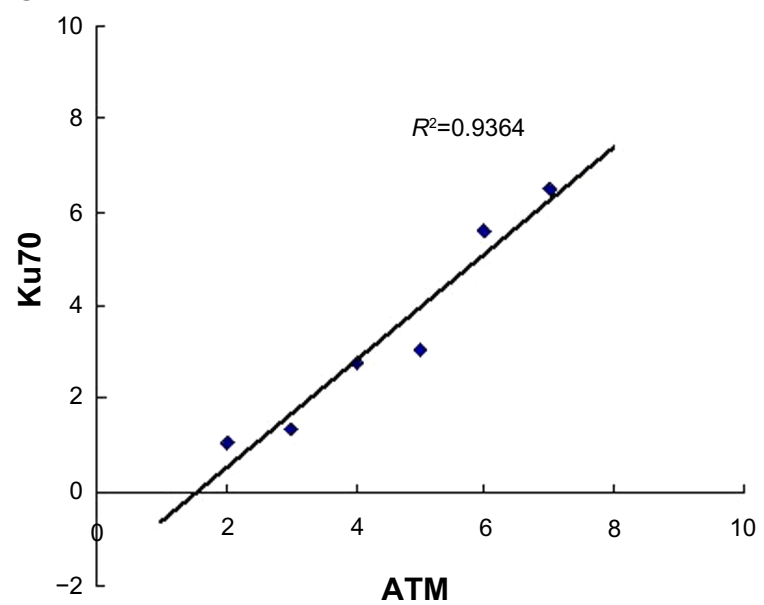

Figure I Ku70 and ATM expression in the colorectal cancer and peri-cancer tissues.

Notes: (A) Western blot analysis of Ku70 and ATM expression was studied in different group of cancer (C) and peri-cancer normal tissue (N). **P $<0.01$. (B) Quantitative real-time PCR analysis of Ku70 and ATM in II2 colorectal cancer and normal tissues. Quantified data were normalized to the housekeeping control of $\beta$-actin. (C) Correlation between Ku70 and ATM expression in the real-time QPCR assay $(* * P<0.01)$.

Abbreviations: ATM, ataxia-telangiectasia mutated; PCR, polymerase chain reaction; QPCR, quantitative polymerase chain reaction; mRNA, messenger RNA.

Table I Expression of Ku70 and ATM and relationship with clinicopathological factors in CRC

\begin{tabular}{|c|c|c|c|c|c|c|c|}
\hline \multirow{2}{*}{$\begin{array}{l}\text { Clinicopathological } \\
\text { indexes }\end{array}$} & \multirow[t]{2}{*}{$\mathbf{n}$} & \multicolumn{2}{|c|}{ Ku70 expression } & \multirow[t]{2}{*}{ P-value* } & \multicolumn{2}{|c|}{ ATM expression } & \multirow[t]{2}{*}{ P-value* } \\
\hline & & Negative & Positive & & Negative & Positive & \\
\hline \multicolumn{8}{|l|}{ Lymph node metastasis ${ }^{\mathrm{a}}$} \\
\hline No & 50 & 26 & 24 & $<0.001$ & 27 & 23 & $<0.001$ \\
\hline $\mathrm{NI}-2$ & 62 & 45 & 17 & & 44 & 18 & \\
\hline \multicolumn{8}{|l|}{ TNM stage $^{a}$} \\
\hline I-II & 49 & 26 & 23 & $<0.001$ & 24 & 25 & $<0.001$ \\
\hline III-IV & 63 & 48 & 15 & & 44 & 19 & \\
\hline
\end{tabular}

Notes: *Statistical analysis was estimated with $\chi^{2}$ test, and $P<0.05$ was considered statistically significant; ${ }^{\text {agrading }}$ of differentiation status and TNM classification for colorectal cancer were based on the American Joint Committee on Cancer Staging Manual (7th edition, 20I0). The tumors were classified into two groups: well differentiated (grades I and II) and poorly differentiated (grades III and IV).

Abbreviations: ATM, ataxia-telangiectasia mutated; CRC, colorectal cancer; TNM, tumor node metastasis. 
A

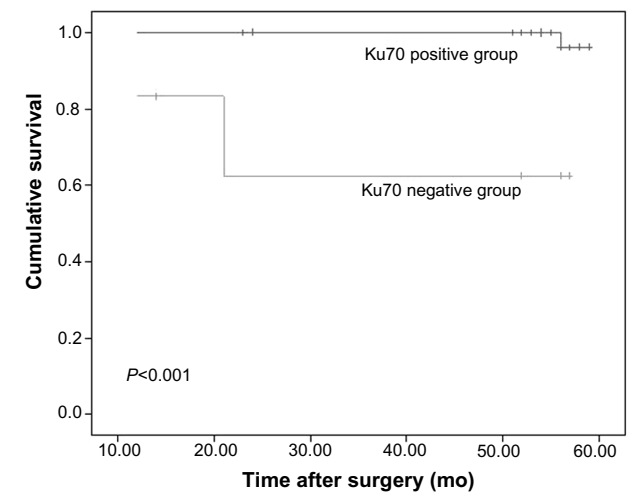

B

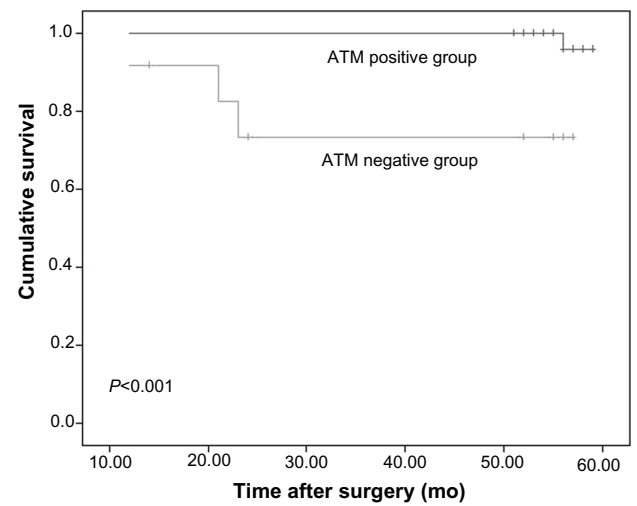

Figure 2 Expression of Ku70 and ATM correlated with poor prognosis in colorectal cancer patients.

Notes: (A) Cumulative overall survival between the Ku70-negative and Ku70-positive group $(P<0.00$ I, log-rank test). (B) Cumulative overall survival between the ATMnegative and ATM-positive group $(P<0.00$ I, log-rank test).

Abbreviations: ATM, ataxia-telangiectasia mutated; mo, months.

Several studies on cell lines and knock-out mice suggest that nonfunctional NHEJ might be the key factor in increasing genomic instability and leading to cancer progression. ${ }^{15-17}$ The current work shows that the downexpression of $\mathrm{Ku} 70$ and ATM, the key proteins of the nonhomologous end-joining pathway of DNA DSB repair, differ obviously between CRC groups and normal tissues, and expression of $\mathrm{Ku} 70$ and ATM are related to CRC clinicopathologic variables including overall survival, whereas the results from Grabsch et al showed that expression of Ku70 was not different in $\mathrm{CRC}$ and normal colon mucosa and bore no relationship to the clinicopathologic variables including patient survival. ${ }^{18}$ From Tables 1 and 2, the low expression of Ku70 affects obviously on the clinicopathological factors, for example, lymph node metastasis and the TNM stage. These results are similar to those from Komuro et al. ${ }^{19}$ This is an interesting point because the investigated populations differed in the studies of Grabsch et al and Komuro et al. Results of our study and the Komuro et al together imply that Ku70 expression is more sensitive among Asians.

Other studies have also demonstrated that reduced ATM expression is related to worse survival in patients

Table 2 Univariate and multivariate analyses of recurrence and survival (Cox regression)

\begin{tabular}{|c|c|c|c|c|}
\hline \multirow[t]{2}{*}{ Variables } & \multicolumn{2}{|l|}{ Recurrence } & \multicolumn{2}{|l|}{ Survival } \\
\hline & HR (95\% Cl) & $P$-value & HR (95\% Cl) & $P$-value \\
\hline \multicolumn{5}{|l|}{ Univariate analysis } \\
\hline \multicolumn{5}{|c|}{ Lymph node metastasis } \\
\hline $\mathrm{N} 0 / \mathrm{NI}-2$ & $2.663(1.472-4.872)$ & 0.012 & $2.712(1.442-5.483)$ & 0.022 \\
\hline \multicolumn{5}{|l|}{ TNM stage } \\
\hline I-II/III-IV & $3.454(1.872-6.466)$ & $<0.001$ & 3.367 (1.577-6.284) & $<0.001$ \\
\hline \multicolumn{5}{|l|}{ Ku70 expression } \\
\hline Negative/positive & $3.453(1.861-6.872)$ & $<0.001$ & $4.182(1.783-8.788)$ & $<0.001$ \\
\hline \multicolumn{5}{|l|}{ ATM expression } \\
\hline Negative/positive & $3.114(1.182-7.122)$ & $<0.001$ & $4.113(1.876-8.432)$ & $<0.001$ \\
\hline \multicolumn{5}{|c|}{ Multivariate analysis } \\
\hline \multicolumn{5}{|c|}{ Lymph node metastasis } \\
\hline No/NI-2 & $0.222(0.021-0.655)$ & 0.045 & $0.186(0.024-0.882)$ & 0.018 \\
\hline \multicolumn{5}{|l|}{ TNM stage } \\
\hline I-II/III-IV & $8.775(2.122-38.102)$ & 0.004 & $9.137(1.683-48.024)$ & 0.009 \\
\hline \multicolumn{5}{|l|}{ Ku70 expression } \\
\hline Negative/positive & $2.536(1.224-6.121)$ & 0.019 & 3.111 (1.336-7.895) & 0.023 \\
\hline \multicolumn{5}{|l|}{ ATM expression } \\
\hline Negative/positive & $2.161(1.108-5.624)$ & 0.011 & $2.764(1.226-7.422)$ & 0.027 \\
\hline
\end{tabular}

Abbreviations: $\mathrm{HR}$, hazard ratio; $\mathrm{Cl}$, confidence interval; TNM, tumor node metastasis; ATM, ataxia-telangiectasia mutated. 
with CRC. ${ }^{20,21}$ DFS associated with ATM expression is independent of the tumor stage (invasion depth [PT] and lymph node metastasis [PN]), which suggests that downexpression of these proteins is an early event in colorectal carcinogenesis.

Accumulated DNA damage has been proposed as a principal mechanism of infection, inflammation, cancer, and aging. ${ }^{22-24}$ ATM acts as the double-strand DNA break signal transducer in the form of DSBs. ${ }^{25,26}$ Mediated by ATM, DNA repair protein $\mathrm{Ku} 70 / 80$ is translocated into the nucleus once DNA damage occurs. ${ }^{27-29}$ The Ku70/Ku80 heterodimer binds to broken DNA ends at a DSB; these proteins might also influence signaling in the DNA damage response, particularly ATM activation. ${ }^{30-32}$ DNA damage response results in the process of $\mathrm{CRC}$ carcinogenesis, of which the $\mathrm{Ku} 70$ / ATM signal pathway is a key mediator. Our data show that downregulated $\mathrm{Ku} 70$ and ATM coexpression occurs in cancer tissues but not in normal tissues. Moreover, both of $\mathrm{Ku} 70$ and ATM expression pattern in CRC samples might add their potential prognostic value to the clinical therapy of tumor, and tumors with bad LNM or TNM stages tend to have negative expression of $\mathrm{Ku} 70$ and ATM. Suitable management in clinical treatment of CRC might be effected through examining the Ku70 and ATM expression patterns. Therefore, the expression pattern of $\mathrm{Ku} 70$ and ATM raises the predictive possibility for tumor clinical management.

In summary, we found downregulation of $\mathrm{Ku} 70$ and ATM, two key proteins involved in the DNA DSB, co-occurred in CRC tissues in Chinese patients, and was associated with poor DFS. Loss of Ku70 and ATM expression might serve as a biomarker that predicts poor prognosis in CRC.

\section{Acknowledgment}

This project was supported by the research grant from Guangxi Key Laboratory of Molecular Medicine in Liver Injury and Repair.

\section{Disclosure}

The authors report no conflict of interest in this work.

\section{References}

1. DeVita VT Jr, Hellmann S, Rosemberg SA. Cancer-Principles and Practice of Oncology. Vol. 28. Philadelphia, New York: Lippincott-Raven; 1997:1144-1197.

2. Fearon ER, Vogelstein B. A genetic model for colorectal tumorigenesis. Cell. 1990;61(5):759-767.

3. Rouse J, Jackson SPF. Interfaces between the detection, signaling, and repair of DNA damage. Science. 2002;297(5581):547-551.

4. Khanna KK, Jackson SP. DNA double-strand breaks: signaling, repair and the cancer connection. Nat Genet. 2001;27(3):247-254.
5. van Gent DC, Hoeijmakers JHJ, Kanaar R. Chromosomal stability and the DNA double-strand break connection. Nat Rev Genet. 2001;2(3):196-206.

6. Zhou BB, Elledge SJ. The DNA damage response: putting checkpoints in perspective. Nature. 2001;408(6811):433-439.

7. Mills KD, Ferguson DO, Alt FW. The role of DNA breaks in genomic instability and tumorigenesis. Immunol Rev. 2003;194:77-95.

8. Chen G, Yuan SS, Liu W, et al. Radiation-induced assembly of Rad51 and Rad52 recombination complex requires ATM and c-Abl. J Biol Chem. 1999;18(274):12748-12752.

9. AJCC. Cancer Staging Handbook. 7th ed; 2010. Available from: http:// www.cancerstaging.org/staging/index.html. Access November.

10. Livak KJ, Schmittgen TD. Analysis of relative gene expression data using real-time quantitative PCR and the 2(-Delta Delta C(T)) method. Methods. 2001;25(4):402-408.

11. Jeggo P, Singleton B, Beamish H, Priestley A. Double strand break rejoining by the Ku-dependent mechanism of non-homologous end-joining. C R Acad Sci III. 1999;322(2-3):109-112.

12. Featherstone C, Jackson SP. DNA double-strand break repair. Curr Biol. 1999;9(20):R759-R761.

13. Walker JR, Corpina RA, Goldberg J. Structure of the Ku heterodimer bound to DNA and its implications for double-strand break repair. Nature. 2001;412(6847):607-614.

14. Kühne C, Tjörnhammar ML, Pongor S, Banks L, Simoncsits A. Repair of a minimal DNA double-strand break by NHEJ requires DNA-PKcs and is controlled by the ATM/ATR checkpoint. Nucleic Acids Res. 2003;31(24):7227-7237.

15. Lanuszewska J, Widlak P. The truncation of Ku86 in human lymphocytes. Cancer Lett. 2004;205(2):197-205.

16. Lieber MR, Ma Y, Pannicke U, Schwarz K. Mechanism and regulation of human non-homologous DNA end-joining. Nat Rev Mol Cell Biol. 2003;4(9):712-720.

17. Choi EK, Lee YH, Choi YS, et al. Heterogeneous expression of Ku70 in human tissues is associated with morphological and functional alterations of the nucleus. J Pathol. 2001;198(1):121-130.

18. Grabsch H, Dattani M, Barker L, et al. Expression of DNA double-strand break repair proteins ATM and BRCA1 predicts survival in colorectal cancer. Clin Cancer Res. 2006;5(12):1494-1500.

19. Komuro Y, Watanabe T, Hosoi Y. The expression pattern of Ku correlates with tumor radiosensitivity and disease free survival in patients with rectal carcinoma. Cancer. 2002;95(6):1199-1205.

20. Beggs AD, Domingo E, McGregor M, et al. Loss of expression of ATM is associated with worse prognosis in colorectal cancer and loss of Ku70 expression is associated with CIN. Oncotarget. 2012;3(11):1348-1355.

21. Morio T, Kim H. Ku, Artemis and ataxia-telangiectasia-mutated: signaling networks in DNA damage. Int J Biochem Cell Biol. 2008;4(40):598-603.

22. Wang JY, Wen LL, Huang YN, Chen YT, Ku MC. Dual effects of antioxidants in neurodegeneration: direct neuroprotection against oxidative stress and indirect protection via suppression of gliamediated inflammation. Curr Pharm Des. 2009;12(27):3521-3533.

23. Ponnala S, Veeravalli KK, Chetty C, Dinh DH, Rao JS. Regulation of DNA repair mechanism in human glioma xenograft cells both in vitro and in vivo in nude mice. PLoS One. 2011;6(10):31-40.

24. Singh K, Matsuyama S, Drazba JA, Almasan A. Autophagy-dependent senescence in response to DNA damage and chronic apoptotic stress. Autophagy. 2012;8(2):236-251.

25. Khanna KK, Keating KE, Kozlov S, et al. ATM associates with and phosphorylates p53: mapping the region of interaction. Nat Genet. 2008;20(4):398-400.

26. Carson CT, Schwartz RA, Stracker TH, Lilley CE, Lee DV, Weitzman MD. The Mre11 complex is required for ATM activation and the G2/M checkpoint. EMBO J. 2003;22(24):6610-6620.

27. Niida H, Nakanishi M. DNA damage checkpoints in mammals. Mutagenesis. 2006;21(1):3-9. 
28. Uziel T, Lerenthal Y, Moyal L, Andegeko Y, Mittelman L, Shiloh Y. Requirement of the MRN complex for ATM activation by DNA damage. EMBO J. 2003;22(20):5612-5621.

29. Buck D, Malivert L, de Chasseval R, et al. Cernunnos, a novel nonhomologous end-joining factor, is mutated in human immunodeficiency with microcephaly. Cell. 2006;124(2):287-299.

30. Downs JA, Jackson SP. A means to a DNA end: the many roles of Ku. Nat Rev Mol Cell Biol. 2004;5(5):367-378.
31. Drouet J, Frit P, Delteil C, de Villartay JP, Salles B, Calsou P. Interplay between $\mathrm{Ku}$, Artemis, and DNA-dependent protein kinase catalytic subunit at DNA ends. J Biol Chem. 2006;281(38):27784-27793.

32. Lieber MR, Ma Y, Pannicke U, Schwarz K. Mechanism and regulation of human non-homologous DNA end-joining. Nat Rev Mol Cell Biol. 2003;4(9):712-720.

\section{Publish your work in this journal}

OncoTargets and Therapy is an international, peer-reviewed, open access journal focusing on the pathological basis of all cancers, potential targets for therapy and treatment protocols employed to improve the management of cancer patients. The journal also focuses on the impact of management programs and new therapeutic agents and
Dovepress

protocols on patient perspectives such as quality of life, adherence and satisfaction. The manuscript management system is completely online and includes a very quick and fair peer-review system, which is all easy to use. Visit http://www.dovepress.com/testimonials.php to read real quotes from published authors.

Submit your manuscript here: http://www.dovepress.com/oncotargets-and-therapy-journal 